\title{
Cuerpos y desplazamientos en \\ Viajes virales: la crisis del contagio global en la escritura del Sida, de Lina Meruane*
}

(Fondo de Cultura Económica, Chile, 2012)

\author{
Juan Pablo Sutherland \\ Escritor, Universidad ARCIS \\ juanpablo.sutherland@gmail.com
}

\section{Escrituras y desplazamientos}

Al comenzar a leer el libro de Lina Meruane, uno puede encontrarse con señales algo equívocas o distractoras. Por el título se puede pensar que es un libro definido obviamente por el cruce entre literatura y sida, cuestión que no está lejos de su construcción. Sin embargo, mi sorpresa ha sido mayor en la medida en que es un libro que funciona como una maquinaria de lectura, no solo pensando en las escrituras, sus imaginarios y el impacto de la epidemia en las literaturas periféricas o escrituras minoritarias, y digo minoritarias, pues será uno de los ejes de mi lectura. Me refiero, más bien, al enfoque de resistencia y agudeza política que nos presenta Viajes Virales y sus dispositivos de lectura. Me sorprende gratamente que Lina Meruane haya escrito un ensayo lúcido, agudo y batallante que no solo aborda políticamente la idea de contaminación entre imaginarios culturales, escrituras y sida, sino que nos proponga una labor mayor, una lectura biopolítica del sida en tiempos neo-liberales, lectura que no deja de estar presente como propuesta a lo largo del libro. Alguna vez junto a Pedro Lemebel comentamos que faltaba un libro que abordará los imaginarios que el sida había provocado o dejado como residuos culturales en América

* El siguiente texto fue leído en una versión más extensa en la presentación de Viajes virales: la crisis global en la escritura del sida, cuyo lanzamiento se realizó en Feria Internacional del Libro de Santiago, 8 de Noviembre de 2012. 
Latina. Un libro que debiera, por lo menos para nosotros, realizar los tránsitos, caminatas y cruces que las locas habíamos hecho arrancando, cayendo y enfrentando a la epidemia. En ese horizonte y registro, creo que Lina nos ganó el quien vive y nos trajo este libro que provocará no solo una lectura particular y localizada de la literatura y la epidemia, sino que dará un aire fresco para re-pensar las políticas del sida, como diría Susan Sontag. Creo firmemente que Lina ha escrito un ensayo que se transformará en el ACT UP de la reflexión crítica del sida. Territorio que me parece relevante en la medida en que la ensayista no habla solo desde un enfoque disciplinario anclado en la literatura, que a estas alturas se supone que está en crisis, sino que más bien realiza una propuesta de lectura que inocula resistencia crítica al interior de las políticas hegemónicas que han leído la epidemia desde el poder, la clase y el ordenamiento de los cuerpos. Por otra parte, el libro se hace cargo de viajes, colonizaciones, idas y vueltas, discusiones críticas y culturales que han rodeado sus políticas. Me parece que el momento del saber entre los campos de la literatura y sida, aquí ha sido privilegiado como labor del intelectual más que un experto particular, en ese sentido, el despliegue técnico de los saberes, como señalara Derrida, solo exige guiones programáticos que no pertenecen a la competencia política del intelectual.

Viajes virales se divide en dos grandes partes, la primera "Bitácora de un viaje" y la segunda "Viajeros virales". Asistiremos en la organización de la lectura nómade, a una especie de panóptico crítico que mirará los diferentes momentos de la epidemia, la genealogía de la peste, los avatares del paciente 0 , o las especulaciones del origen de la epidemia. Todo ello para politizar un mapa cubierto de señales, rumbos, atajos y recorridos que han construido una sinuosa lectura de una epidemia que ha ido mutando, como también han ido mutando categorías, gobiernos, activismos, cuerpos y políticas de prevención y fondos. Lina nos deja entrar a los archivos desclasificados del control biopolítico que ha significado el sida en América Latina, da cuenta de sus controles demográficos, de sus comunidades diezmadas y de su ojo lector para acusar la recepción crítica de textos.

Aquí nos encontraremos con grandes autores y textos que han levantado metáforas de la peste, 
de la epidemia, de la muerte, del cuerpo y sus hegemonías, de viajes y nuevas colonizaciones. Reconocemos el abanico que va por Reinaldo Arenas, Pedro Lemebel, Néstor Perlongher, Witold Gombrowicz, Mario Bellatin, Pablo Pérez, Lorca, MarchantLazcano, Severo Sarduy, Augusto D' Halmar, Marta Dillon, José Donoso, Manuel Puig, entre algunos de los mencionados. En ese enjambre de autores, no solo se realiza una política de lectura en relación con un momento particular de la epidemia, sino que se releen políticas de identidad, crisis respecto a la masculinidad, se repiensan preguntan viejas, se leen o revisitan textos que nos dan luces del viaje y la identidad en el caso de D' Halmar, o respecto a las colonizaciones del sida, ida y vuelta del continente en Sarduy. Se vuelven a pensar los momentos más fatídicos, se releen los tiempos del sida con Ronald Reagan, se recuerda la conmoción causada por la salida del closet de Rock Hudson, es decir, nos encontramos con una bitácora de viaje que nos promete cuestionar cada momento, pensar los registros, volver a sorprendernos con las persecuciones homofóbicas, volver a pensar las políticas de higiene social en los estados na- cionales. Por otra parte, Viajes Virales se hará preguntas necesarias y tomará posición respecto a violencias y estrategias. Se preguntará asimismo por la ausencia de imaginarios, ausencia de comunidades posibles, al centro o en la periferia de la epidemia, tensionará el lugar de las mujeres, problematizará su invisibilización, gestionará una crítica a las políticas que anclaron a las mujeres en determinados lugares de las políticas del sida. Repasará el primer momento de cierta aura de inmunidad en las mujeres, luego el estigma de la culpa prostibular en otras y la victimización de la heroína esposa.

Así, veremos que el imaginario simbólico y cultural del sida en América Latina ha estado ligado al impacto de la epidemia y las políticas articuladas por gobiernos, sociedad civil, imaginarios producidos por escritores, agencias y ONGs que presentaron diferentes estrategias para frenar la expansión del VIH/SIDA.

En América Latina, tuvimos literatura antes que teoría queer, es decir, ha sido la literatura el territorio que ha desordenado e interrogado categorías de sexo, cuerpo, identidad y clase, definiciones que se han cruzado con la ciudad letrada marica. En esa 
perspectiva, Viajes virales se ha hecho cargo de aquella interrogación que han realizado las escrituras minoritarias en medio de la globalización del sida. Extensión universalizante que ha impuesto inicialmente lógicas de objetivación a los cuerpos vigilados por el estigma de la epidemia. No es menor que el cuerpo homosexual se haga presente en los imaginarios que citan los textos convocados en este libro. Recordemos que la epidemia se reconoce inicialmente a partir de las comunidades homosexuales, y que inicialmente se focaliza en ellas desde el estigma. Cierto es también que el sida ha dejado de ser una epidemia identificada con un solo sector de la población, más bien su extensión abarca otras poblaciones, diversos sectores sociales, pero sus mayores vulnerabilidades se darán en los sectores populares conjugados con una abierta estigmatización y homofobia presentes en nuestras sociedades. Tendríamos que reconocer además que la mayor prevalencia o incidencia del sida en América Latina corresponden a las poblaciones homo-bisexuales. En ese sentido, ese impacto se ha notado en las escrituras presentes en el imaginario de la peste que se ha extendido acompaña- da de los lugares estigmatizantes que la sociedad construyó a través de la epidemia.

La ecuación escritura, enfermedad, sida, cuerpo y homosexualidad, ha provocado un sinnúmero de textos mayores que nos llevan a pensar que el imaginario de la peste y la enfermedad son productores simbólicos de una extensa poética del sida en la literatura latinoamericana.

Las políticas del sida, activismos, hegemonías y embestidas

Finalmente, Viajes virales nos propone una vuelta local y global del sida, repasando sus primeras décadas conservadoras, re-visitando las respuestas de los activistas, de textos y contextos, de los viajes de idas y vueltas de la colonización, y de las muchas que se superponen en un continente como el nuestro. Aquí hay propuesta de lectura políticamente intencionada, provocadora $\mathrm{y}$, por cierto, refrescante desde el género del ensayo. Lina Meruane ha escrito un texto en un lenguaje llano y con una gran densidad crítica. Un libro que despliega autores, textos y sus imaginarios con una guía que huele a pasión lectora y complicidad con sus mundos. Como ya lo he dicho, creo que este libro se 
volverá el ACT UP de la crítica y de las preguntas sobre sida e imaginarios en América Latina.

\section{Bibliografía}

Meruane, Lina. Viajes virales: la crisis del contagio global en la escritura del sida Santiago: Fondo de Cultura Económica, 2012.

Lemebel, Pedro. Loco afán, crónicas de sidario. Santiago: Seix Barral, 2009.
Eribon, Didier. Reflexiones sobre la cuestión gay. Barcelona: Anagrama, 2001.

Sutherland, Juan Pablo. Nación marica, prácticas culturales y crítica activista. Santiago: Ripio ediciones, 2009.

Stanford University, Nuevo texto crítico, 43/44, Volumen XXII, 2009. 